\title{
Foliar treatments with Gaultheria procumbens essential oil induce defense responses and resistance against a fungal pathogen in Arabidopsis
}

\author{
Sophie Vergnes ${ }^{1,2}$, Nathalie Ladouce ${ }^{1,2}$, Sylvie Fournier ${ }^{1,2}$, Hicham Ferhout ${ }^{3}$, Faouzi Attia ${ }^{4,5}$ and \\ Bernard Dumas ${ }^{1,2 *}$
}

1 Université de Toulouse, UPS, Laboratoire de Recherche en Sciences Végétales, Castanet-Tolosan, France

${ }^{2}$ CNRS, Laboratoire de Recherche en Sciences Végétales, Castanet-Tolosan, France

${ }^{3}$ Natex Biotech, Toulouse, France

${ }^{4}$ Equipe Recherches Agronomiques, Agronutrition, Carbonne, France

${ }^{5}$ LabCom C2R-BIONUT, Toulouse, France

\section{Edited by:}

Ebrahim Hadavi, Islamic Azad

University, Iran

Reviewed by:

Grama Nanjappa Dhanapal,

University of Agricultural Sciences,

Bengaluru, India

lyyakkannu Sivanesan, Konkuk

University, South Korea

\section{*Correspondence:}

Bernard Dumas, Laboratoire de Recherche en Sciences Végétales, UMR 5546 CNRS Université Paul

Sabatier, 24 Chemin de Borde

Rouge, Auzeville, BP42617,

31326 Castanet-Tolosan, France

e-mail:dumas@|rsv.ups-tlse.fr
Essential oil from Gaultheria procumbens is mainly composed of methylsalicylate (MeSA) (>96\%), a compound which can be metabolized in plant tissues to salicylic acid, a phytohormone inducing plant immunity against microbial pathogens. The potential use of $G$. procumbens essential oil as a biocontrol agent was evaluated on the model plant Arabidopsis thaliana. Expression of a selection of defense genes was detected 1,6 , and $24 \mathrm{~h}$ after essential oil treatment $(0.1 \mathrm{ml} / \mathrm{L})$ using a high-throughput qPCR-based microfluidic technology. Control treatments included methyl jasmonate and a commercialized salicylic acid (SA) analog, benzo $(1,2,3)$-thiadiazole-7carbothiolic acid (BTH). Strong induction of defense markers known to be regulated by the SA pathway was observed after the treatment with $G$. procumbens essential oil. Treatment induced the accumulation of total SA in the wild-type Arabidopsis line Col-0 and analysis of the Arabidopsis line sid2, mutated in a SA biosynthetic gene, revealed that approximately $30 \%$ of MeSA sprayed on the leaves penetrated inside plant tissues and was demethylated by endogenous esterases. Induction of plant resistance by $G$. procumbens essential oil was tested following inoculation with a GFP-expressing strain of the Arabidopsis fungal pathogen Colletotrichum higginsianum. Fluorescence measurement of infected tissues revealed that treatments led to a strong reduction $(60 \%)$ of pathogen development and that the efficacy of the $G$. procumbens essential oil was similar to the commercial product $\mathrm{BION}^{\circledR}$. Together, these results show that the G. procubens essential oil is a natural source of MeSA which can be formulated to develop new biocontrol products.

Keywords: methyl salicylate, Arabidopsis, dynamic array, essential oils, plant immunity

\section{INTRODUCTION}

Plant are constantly challenged by harmful microorganisms and diseases caused by fungal, bacterial, or viral phytopathogens pose severe threats to crop productivity worldwide (Fisher et al., 2012). Controlling plant diseases requires the use of massive amounts of synthetic pesticides, the breeding of resistant plant varieties, and agronomical strategies such as crop rotation. The development of an environmental-friendly and sustainable agriculture drives the search for alternative strategies and among these the use of natural compounds able to stimulate the plant immune system.

Plants possess the intrinsic capacity to respond efficiently to pathogen attacks by mounting immune responses. The first line of microbial perception occurs through the detection of molecular patterns exposed or released by microbial molecules and named PAMPs (or MAMPs; Pathogen (or Microbial) Associated Molecular Patterns). These molecular patterns interact with specialized receptors and the perception of PAMPs induced a signaling cascade which culminates with the expression of defense genes (Boller and Felix, 2009).

Thus, inducing resistance to pathogens by mimicking PAMPs activity could represent an attractive strategy to protect plants against diseases. Several products from natural sources, mainly algal polysaccharides, have been used as plant defense activators. These include $\beta 1,3$ glucan from the brown algae Laminaria digitata, ulvans from the green algae Ulva sp. sulfated fucans and carrageenans (Klarzynski et al., 2000, 2003; Mercier et al., 2001; Jaulneau et al., 2010, 2011). However, probably the most successful commercial compound inducing plant defense reactions is the chemical benzo(1,2,3)-thiadiazole-7carbothiolic acid (BTH) (also named acibenzolar-S-methyl, ASM) (Lawton et al., 1996). BTH has been shown to efficiently control diseases on several crops in field experiments demonstrating that eliciting plant defenses can constitute an alternative strategy to chemical fungicides (Walters et al., 2013). In fact BTH is a functional 
analog of the phytohormone salicylic acid (SA), a major signaling compound controlling the development of a part of immune responses in concert with jasmonic acid (JA) and ethylene. A tightly balance hormonal control determine the type of defense against a given pathogen (Bari and Jones, 2009). SA signaling pathway has been implicated in the induction of defense against biotrophic pathogens and acts antagonistically of the JA pathway involved against necrotrophs (Glazebrook, 2005). SA produced at the infection site is the initial signal which engages the systemic induction of defense responses, a phenomenon called Systemic Acquired Resistance (SAR). Construction of transgenic plants expressing a bacterial salicylate hydroxylase able to convert SA to the inactive product catechol, demonstrated the essential role of SA in SAR (Delaney et al., 1994). In Arabidopsis, accumulation of SA induces the nuclear localization of the central immune regulator Non Expressor of Pathogenesis-Related Protein 1 (NPR1). NPR1 is a transcriptional regulator which controls the expression of a wide range of SAR-related genes, among these genes coding the Pathogenesis-Related 1 protein (PR1) (Pajerowska-Mukhtar et al., 2013).

Two biosynthetic pathways are involved in the biosynthesis of SA derived from phenylalanine or chorismic acid. In Arabidopsis, the chorismic acid pathway is the major route to SA. Chorismic acid is the substrate of isochorismate synthases (ICSs) which produce isochorismate, a direct precursor of SA. The essential role of ICSs genes has been demonstrated by the isolation of mutants such as sid2 (Wildermuth et al., 2001). In sid2 mutants, accumulation of SA upon pathogen infection reaches only $5-10 \%$ of wild type level (Wildermuth et al., 2001). However, it has been shown from grafting experiments that SA is not the mobile signal inducing SAR (Vernooij et al., 1994). Several mobile signals have been identified including the methylated SA derivative, methyl SA (MeSA), a dicarboxylic acid, azelaic acid (AzA), an abietane diterpenoid, dihydroabetinal (DA), and a phosphorylated sugar derivative, glycerol-3-phosphate (G3P) (Shah et al., 2014). While the function of these metabolites depends on SA, only MeSA is directly linked to SA synthesis since this compound is produced upon the transfer of a methyl group from the donor S-adenosyl methionine methylation catalyzed by a SAmethyltransferase (SAMT). In tobacco, silencing of a SAMT gene and grafting experiments demonstrated the essential role of MeSA synthesis in the development of SAR upon infection with the tobacco mosaic virus (Park et al., 2007). In the distal leaves, MeSA is converted to SA by the action of MeSA esterases, enzymes which has been shown essential for the expression of SAR in tobacco leaves (Aviv et al., 2002; Park et al., 2007).

Since SAR can protect efficiently plants against a wide range of microbial pathogens, molecules which induce this response can represent an attractive strategy to protect plants. The main advantage of this strategy is the use of non-toxic natural products instead of chemical fungicides which are harmful for the environment. However, the induction of SAR through the salicylate pathway for use in organic agriculture would require the identification of natural sources of active compounds. The plant genus Gaultheria (Ericaceae) includes several species largely present in Asia and North America, growing as evergreen shrub. Most Gaultheria species are regarded as traditional herbal medicine, notably used in the treatment of pain. Highly relevant to this biological activity is the composition of Gaultheria essential oil (GEO) which contains more than 96\% methylsalicylate (MeSA) and several derivatives of MeSA has been identified (Liu et al., 2013; Nikolic et al., 2013).

Here, we used a new high-throughput Q-PCR microfluidic method to analyze in a single Q-PCR run the expression of biomarker genes related to plant defense after treatment of Arabidopsis plant with GEO. Determination of SA levels after treatment of sid2 plants showed that MeSA from GEO is readily absorbed and metabolized by plant tissues. Our results demonstrate that GEO is a natural source of MeSA which can substitute to synthetic SA analogs for agronomic applications.

\section{MATERIALS AND METHODS \\ PLANT, FUNGAL STRAINS, AND CHEMICALS}

Arabidopsis thaliana lines used were Col-0 wild-type, transgenic line PR1-GUS (Shapiro and Zhang, 2001), sid2 (Wildermuth et al., 2001), and NahG mutant plants. For treatment assays, seeds were soaked in water for $40 \mathrm{~min}$, and then treated for $30 \mathrm{~min}$ in $2.4 \%$ sodium hypochlorite solution, followed by four washings in sterile water. The surface-sterilized seeds were transferred into wells of 24-well microtiter plates (2 seeds per well), containing $300 \mu \mathrm{l}$ of Murashige and Skoog medium (MS; Sigma-Aldrich) supplemented with $1 \%$ sucrose. The plates were incubated under $16 \mathrm{~h}$ illumination period $\left(270 \mu \mathrm{mol} \mathrm{m} \mathrm{m}^{-2} \mathrm{~s}^{-1}\right)$ and $8 \mathrm{~h}$ night period at $23^{\circ} \mathrm{C}$ on a rotary shaker at $90 \mathrm{rpm}$ for 3 days and then on a static tray for 12 days. For SA analysis and pathogenicity tests, plants were grown on pots (Jiffy, Lyon, France) in a growth chamber under $12 \mathrm{~h}$ light $\left(270 \mu \mathrm{mol} \mathrm{m} \mathrm{m}^{-2} \mathrm{~s}^{-1}\right)$, at $23^{\circ} \mathrm{C}$ and $12 \mathrm{~h}$ dark at $20^{\circ} \mathrm{C}$ during 3 weeks.

A Colletotrichum higginsianum transgenic strain expressing the green fluorescent protein (O'Connell et al., 2004) was used to pathogenicity assays. The strain was grown on Mathur's agar medium (glucose $2.8 \mathrm{~g} / \mathrm{L} ; \mathrm{MgSO}_{4} 1.22 \mathrm{~g} / \mathrm{L} ; \mathrm{KH}_{2} \mathrm{PO}_{4} 2.72 \mathrm{~g} / \mathrm{L}$; peptone $2.8 \mathrm{~g} / \mathrm{L}$; Agar $30 \mathrm{~g} / \mathrm{L}$ ) in the dark at $23^{\circ} \mathrm{C}$. After 10 days of growth, fungal spores were recovered with sterile water and the concentration was adjusted after counting the spores. GEO and synthetic methyl salicylate were obtained from Nat'Ex Biotech (Toulouse, France). Methyl jasmonate was obtained from Sigma-Aldrich. Flg22 peptide was synthesized by Proteogenix (Strasbourg, France) with purity greater than 90\%. Chitin oligomers obtained from Crab shell chitin (CSC, Sigma-Aldrich) were prepared as described by Nars et al. (2013). BTH formulated as $\mathrm{BION}^{\circledR}$ was obtained from Syngenta.

\section{PLANT TREATMENTS}

For the treatment of plant grown in 24-well microtiter plates, chemicals were added in the liquid MS medium after 10 days of growth. Foliar treatments were done on 3-week old plants grown on pot by spraying $1 \mathrm{ml} /$ pot of the chemicals using a manual spray.

\section{GUS ACTIVITY ASSAYS}

Total proteins were extracted from $100 \mathrm{mg}$ of treated plants after grinding in liquid nitrogen, with $100 \mu \mathrm{l}$ of GUS buffer (100 mM Phosphate buffer pH7, 0.1\% TritonX-100, $10 \mathrm{mM}$ 
$\beta$-mercaptoethanol) (Jefferson et al., 1987). Glucuronidase activity was measured by fluorometric assay with $25 \mu \mathrm{l}$ of protein extracts and $1 \mathrm{mM}$ MUG (4-methylumbelliferyl glucuronide, Sigma) in a total reaction volume of $200 \mu$ l. Fluorescence was measured every $5 \mathrm{~min}$ during $120 \mathrm{~min}$ on a TriStar LB 941 Multimode Microplate Reader (Berthold Technologies) at $37^{\circ} \mathrm{C}$ with $360 \mathrm{~nm}$ excitation and $460 \mathrm{~nm}$ emission. The fluorimeter was calibrated with freshly prepared MU (4-methylumbelliferone sodium salt, Sigma-Aldrich) standards in the same GUS buffer. Protein concentration was determined by the method of Bradford on 96 well plates. Two hundred microliter of Bradford reagent (Bio-Rad Laboratories) were added to $10 \mu \mathrm{l}$ of samples. After incubation ( $15 \mathrm{~min}, 25^{\circ} \mathrm{C}$ ), absorbance was measured at $565 \mathrm{~nm}$. Standard curve was done with 1-20 $\mu \mathrm{g}$ of BSA (Sigma-Aldrich). Glucuronidase activity was calculated from the linear part of the reaction (between 20 and $100 \mathrm{~min}$ ) and expressed as nkatal/mg of total proteins.

\section{GENE EXPRESSION ANALYSIS}

Total RNAs were extracted using the SV Total RNA Isolation System kit (Promega ${ }^{\circledR}$, Charbonnières, France). For each sample, $1 \mu \mathrm{g}$ of total RNA was reverse-transcripted with the High-Capacity cDNA Reverse Transcription Kit (Applied Biosystems $^{\circledR}$, Courtaboeuf, France). High-throughput Q-PCR was performed using the BioMarkTM HD System (Fluidigm ${ }^{\circledR}$, Issy les Moulineaux, France). Briefly, cDNAs were diluted to $\sim 50 \mathrm{ng} / \mu \mathrm{l}$ prior to be submitted to specific target amplification (STA) by 14 cycles of PCR amplification $\left(95^{\circ} \mathrm{C}\right.$ for $15 \mathrm{~s}$ and $60^{\circ} \mathrm{C}$ for $4 \mathrm{~min}$ ) in a reaction mix containing the 96 primer pairs $(50 \mathrm{nM})$ and the TaqMan ${ }^{\circledR}$ PreAmp Master Mix (1:2) (Applied Biosystems $^{\circledR}$, Courtaboeuf, France). Primer sequences are presented in the Table S1. Pre-amplified cDNAs were diluted with TE buffer (1:5) and used for Q-PCR array analysis in a reaction mix containing TaqMan Gene expression Master mix, DNA Binding Dye Sample Loading Reagent and EvaGreen ${ }^{\circledR}$. Data were analyzed with the BioMark Real-Time PCR Analysis Software Version 2.0 (Fluidigm). The NormFinder software (Andersen et al., 2004) was used to determine the best housekeeping genes. Relative gene expression was calculated over three independent experiments and significant gene deregulations were determined by student $t$-test.

\section{SA ANALYSIS}

For determination of SA content, $100 \mathrm{mg}$ of leaf tissue were ground in liquid nitrogen, and $50 \mathrm{ng}$ of an internal standard (o-anisic acid, oANI) were added before the extraction of total SA. Total SA (free SA and SA conjugates) was extracted by methanolic extraction followed by acid hydrolysis. The hydrolysate was then subjected to organic phase partitioning (ether). After extraction, organic phase was evaporated and sample diluted with $100 \mu \mathrm{l}$ of acetonitrile/water/formic acid (50/50/0.1\%, v/v/v). Analysis was performed with a reversed phase high-performance liquid chromatography (HPLC, Ultimate 3000, ThermoScientific) coupled with fluorescence detection (Jasco FP-920). SA and oANI were separate on a XBridge reverse phase column $(25 \mathrm{~cm} \times$ $4.6 \mathrm{mms} \times 5 \mu \mathrm{m}$, Waters $)$ and a XBridge guard column $(2 \mathrm{~cm} \times$ $4.6 \mathrm{~mm} \times 5 \mu \mathrm{m}$, Waters) by gradient elution with a binary system of acetonitrile-water-formic acid. Mobile phase consisted of acetonitrile-formic acid (100: 0.1\%, v/v) and water-formic acid (100: $0.1 \%, \mathrm{v} / \mathrm{v})$ at a flow rate of $0.8 \mathrm{~mL} / \mathrm{min}$. Fluorescence detection set at excitation/emission wavelengths $294 / 359 \mathrm{~nm}$ for oANI and $305 / 407 \mathrm{~nm}$ for SA. SA was quantified using Chromeleon 6.8 chromatography software (ThermoScientific). Corrections for losses were made for each individual sample according to recoveries of the internal standard.

\section{PATHOGENICITY TESTS}

Infection tests were performed on 3 weeks old A. thaliana Col-0 plants. Foliar tissues were sprayed with $\mathrm{BION}^{\circledR}$ or GEO and inoculation was done $48 \mathrm{~h}$ after treatment. A spore suspension of C. higginsianum-GFP at $10^{5}$ spores/ml was sprayed on the plants. The fungal colonization was evaluated after 7 days by GFP quantification. Proteins were extracted from $100 \mathrm{mg}$ of five aerial parts of plants after grinding in liquid nitrogen, with $200 \mu \mathrm{l}$ of extraction buffer (100 mM Phosphate buffer pH7, 0.1\% TritonX-100, $100 \mathrm{mM} \mathrm{NaCl}, 10 \mathrm{mM}$ EDTA, and $1 \mathrm{mM}$ PMSF). GFP fluorescence was measured on $200 \mu \mathrm{l}$ of protein extracts with $485 \mathrm{~nm}$ excitation and $535 \mathrm{~nm}$ emission during $1 \mathrm{~min}$ on TriStar LB 941 Multimode Microplate Reader (Berthold Technologies) and expressed in RFU (Relative Fluorescence Unit).

\section{RESULTS}

\section{DOSE-DEPENDENT INDUCTION OF THE SAR MARKER PR1 BY GEO}

As a first approach to study GEO elicitor activity, PRI-GUS plants (Shapiro and Zhang, 2001) grown in microtiter plates were incubated in GEO solutions at various concentrations and $\beta$ glucuronidase activity was measured $48 \mathrm{~h}$ after treatment. A 5 fold increase in $\beta$ glucuronidase activity was observed at the lowest GEO concentration $(0.2 \mu \mathrm{l} / \mathrm{ml})$, reaching a maximum activity (25 fold increase) at $2 \mu \mathrm{l} / \mathrm{ml}$ with no symptom of phytotoxicity (Figure 1). A concentration of $1 \mathrm{ml} / \mathrm{L}$ was chosen for further studies.

\section{INDUCTION OF GENE EXPRESSION UPON GEO TREATMENTS}

To construct a diagnostic chip to monitor plant defense responses, marker genes corresponding to various classes of immune responses were selected by mining transcriptomic databases (Winter et al., 2007; Hruz et al., 2008) and bibliographic data (Table S2). The categories selected included genes induced by phytohormones (SA, JA, ethylene, and absicic acid), by microbial PAMPs (FLG22, chitosaccharides, harpin, and lipopolysaccharides), pathogen infection and housekeeping genes. To validate the selection of marker genes, Arabidopsis plants (Col-0) grown in microtiter plates were treated with solutions containing mehyljasmonate (MeJA), FLG22 peptide, BTH (BION ${ }^{\circledR}$ formulation), and chitosaccharidic fragments obtain from crab shell chitin (DP 6-9) (Nars et al., 2013). RNAs were extracted 1, 6 , and $24 \mathrm{~h}$ after treatments and gene expression was analyzed by real-time quantitative-RT PCR using the dynamic array (Figure 2). Normalization was done using the standard gene AT5G46630 encoding a clathrin adaptor complex medium subunit family protein, selected upon analysis of the results with the Normfinder algorithm (Andersen et al., 2004). Genes falling in the JA and SA category were mainly up-regulated following 
the corresponding treatment (MeJA and $\mathrm{BION}{ }^{\circledR}$, respectively), excepted for the WAK1 gene (At1G21250) and the ankyrin gene (At5G54610) which showed a strong up-regulation $1 \mathrm{~h}$ after treatment by both phytohormones. Similar induction of PAMPinduced markers was obtained following Flg22 and COS treatment. Together these results show that the selection of marker genes used combined with the microfluidic dynamic array is a useful approach to determine the activity of plant immunity elicitors.

The dynamic array was used to determine the activity of GEO. The product was mixed with a wetting agent and spray at $0.1 \%$ final concentration on Col-0 leaves. Expression of marker genes by the microfluidic dynamic array was determined 1,6 , and $24 \mathrm{~h}$ after the treatment. GEO strongly induced SA marker genes but

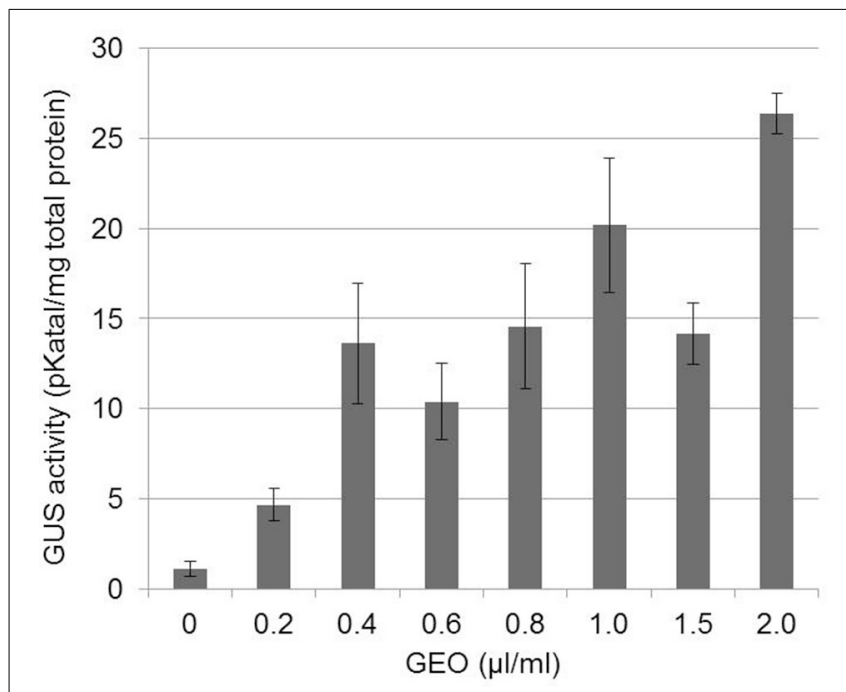

FIGURE 1 | Dose-dependent induction of PR1::GUS gene by GEO foliar treatments. PR1::GUS Arabidopsis leaves were treated with various concentrations of GEO. GUS activity was determined $48 \mathrm{~h}$ after the treatment. Three independent biological experiments were performed for each condition. Bars: standard error to the mean. not genes falling into other categories (Figure 2) suggesting that GEO activity is mainly due to MeSA. To confirm this result, GEO activity was compared with the activity of pure MeSA. $\beta$-glucuronidase activity from GEO or MeSA treated-PR1::GUS plants were analyzed $48 \mathrm{~h}$ after the treatment. A similar induction of the glucuronidase activity was observed (Figure 3). Expression of a selection of defense genes was analyzed by real-time quantitative RT-PCR. Again, similar values were obtained in both treatments showing that GEO display a comparable activity to MeSA (Figure 3).

\section{ACCUMULATION OF SALICYLIC ACID IN WILD-TYPE AND sid2 PLANTS TREATED WITH GEO}

The effect of GEO on SA accumulation was studied on wildtype Col-0 plants, sid2 plants mutated in the gene coding the SA biosynthetic enzyme ICS (Wildermuth et al., 2001) and NahG plant expressing a bacterial SA hydroxylase. The rationale behind the use of sid2 plants was to determine the proportion of external MeJA which accumulate inside the plant tissues and subsequently demethylated by endogenous esterases. Treatments of Col-0 plants with GEO solution led to a strong increase of total SA content in treated leaves. The background level of SA was found to be lower in control sid2 and NahG plants compared to Col-0. However, treatment with GEO led to an increase of SA content only in sid2 plants and not in NahG leaves (Figure 4). This suggests that MeSA from GEO penetrated sid2 leaves and was efficiently demethylated by endogenous SA esterases.

\section{TREATMENT WITH GEO PROTECTS PLANT TO FUNGAL INFECTION}

To evaluate the effect of GEO treatment on fungal disease, we used the Arabidopsis pathogen C. higginsianum (O'Connell et al., 2004). Col-0 plants treated with the wetting agent or with a solution containing GEO at $0.1 \%$ were inoculated with a conidial suspension of a GFP-expressing C. higginsianum strain. Six days after inoculation, $\mathrm{BION}^{\circledR}$ and $\mathrm{GEO}$ treated-leaves showed reduced symptoms compared to control plants (Figure 5). Quantification of GFP-fluorescence indicated a reduction of about $60 \%$ of the fungal development in treated-leaves (Figure 5). Additionally, the

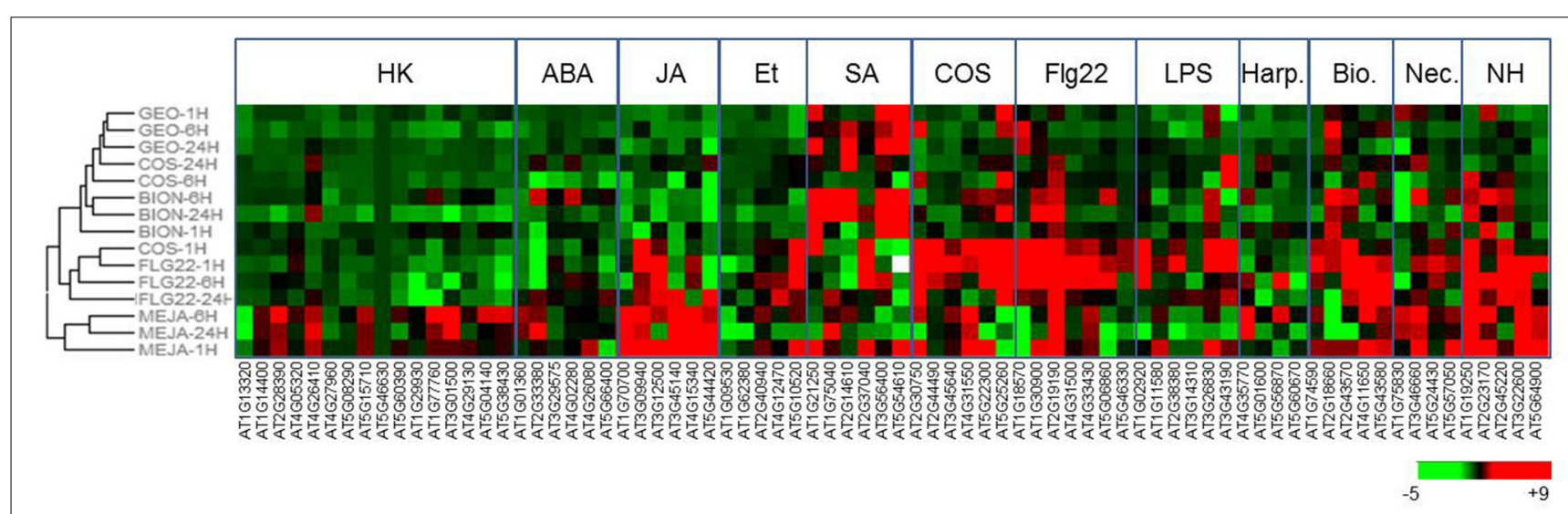

FIGURE 2 | GEO treatment induces SA-regulated defense genes. Gene expression after GEO treatment of Arabidopsis leaves with various compounds (MeJA, SA, FLG22, COS, BION, GEO) was analyzed using the microfluidic dynamic array. Treatments were clustered using the HCE clustering software and default parameters. 


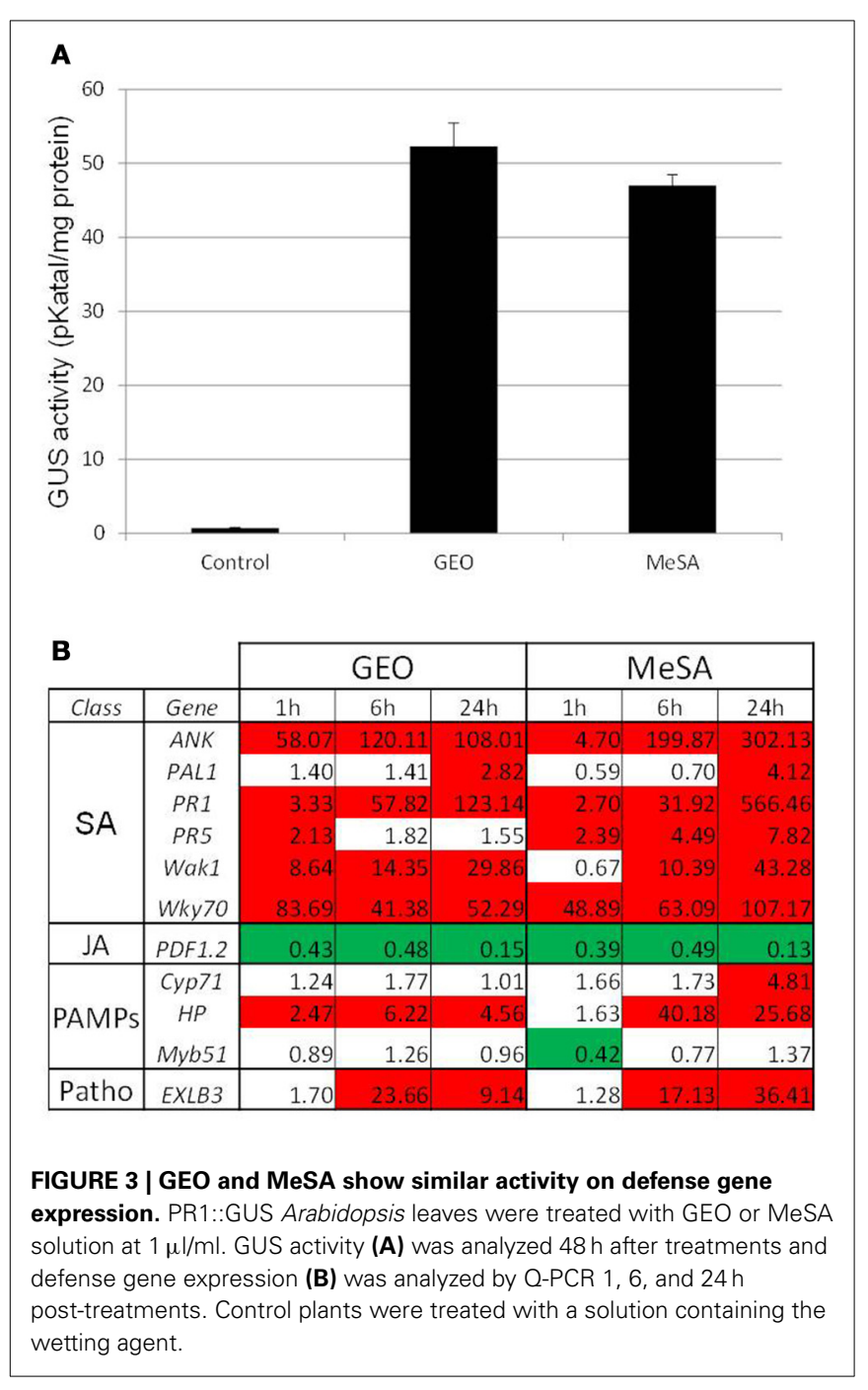

effect of successive GEO, MeSA, and $\mathrm{BION}{ }^{\circledR}$ treatments on plant development was also evaluated over a 6 weeks period. It was previously shown that successive treatment of Arabidopsis with BION ${ }^{\circledR}$ can affect several fitness parameters (Van Hulten et al., 2006). Weekly treatments of GEO and MeSA did not induce a detectable effect on plant development (Figure 6). However, weekly BION ${ }^{\circledR}$ treatments led to decrease of about $50 \%$ of aerial part weight of the plants in agreement with previous results (Van Hulten et al., 2006).

\section{DISCUSSION}

Here, we investigate the biological activity of an essential oil from the medicinal plant Gaultheria procumbens. Expression analysis showed that treatment of Arabidopsis leaves induced SAdependent genes, similarly to the SA analog BTH, the active ingredient of the commercialized product $\mathrm{BION}^{\circledR}$, and to MeSA. The potential use of essential oils for the control of plant diseases has been mainly linked to a direct effect on the growth of pathogenic fungi (Yoon et al., 2013). However, a still largely unexplored effect of essential oils could be their activity on plant immunity. While a direct effect of high concentration of GEO on

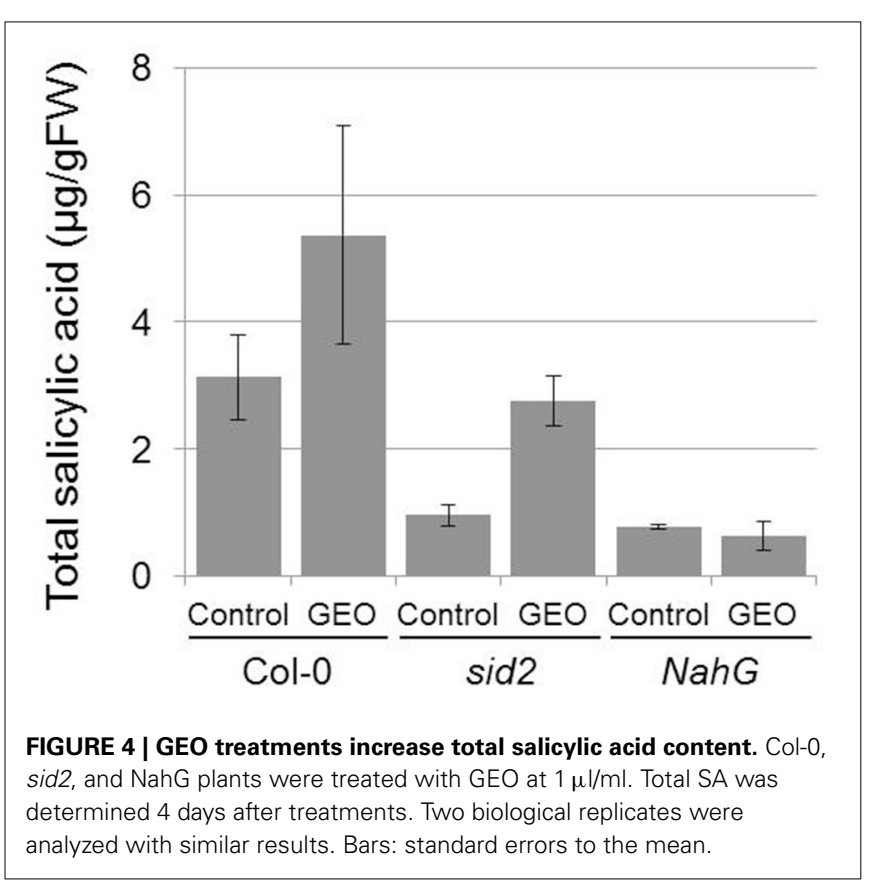

the growth of filamentous fungi was recently reported (Nikolic et al., 2013), we did not observe an inhibitory effect of C. higginsianum growth at a concentration of $1 \mu \mathrm{l} / \mathrm{ml}$ (not shown). These results suggest that MeSA is the main active ingredient of GEO through the induction of SA-dependent immune responses resulting in an increase resistance to pathogenic fungi.

The development of a collection of marker genes representing various classes of immune responses as well as housekeeping genes and the use of a microfluidic high-throughput real-time reverse transcription-Q-PCR platform [the BioMark HD (TM) system from Fluidigm] allowed us to identify the mode of action of GEO. This technology enabled the analysis in a single Q-PCR run of the expression of 96 markers in $96 \mathrm{cDNA}$ preparations. To our knowledge, this system was never used to study the activity of compounds active on plants. While our selection of marker genes was dedicated to identify compounds inducing immune responses, this approach could be used to characterize other types of compounds acting on resistance against abiotic stress or stimulating developmental processes. Thus, the Biomark system could represent an attractive and cost-effective alternative method to other systems based on the use of microarrays (Von Rad et al., 2005).

To determine whether GEO treatment allowed the accumulation of SA inside plant tissues, we used the sid 2 mutant defective in the ICS involved in the main SA biosynthetic pathway in Arabidopsis (Wildermuth et al., 2001). Treatment of sid2 leaves led to accumulation of SA suggesting that MeSA from GEO is efficiently demethylated by $A$. thaliana MeSA esterases. Multiple esterases able to efficiently demethylate MeSA have been identified in A. thaliana (Vlot et al., 2008). The effect of GEO on induced resistance was measured on Arabidopsis leaves inoculated with the fungal pathogen $C$. higginsianum. It has been previously shown that Arabidopsis plants expressing the bacterial salicylate hydroxylase gene NahG are hypersusceptible to C. higginsianum 


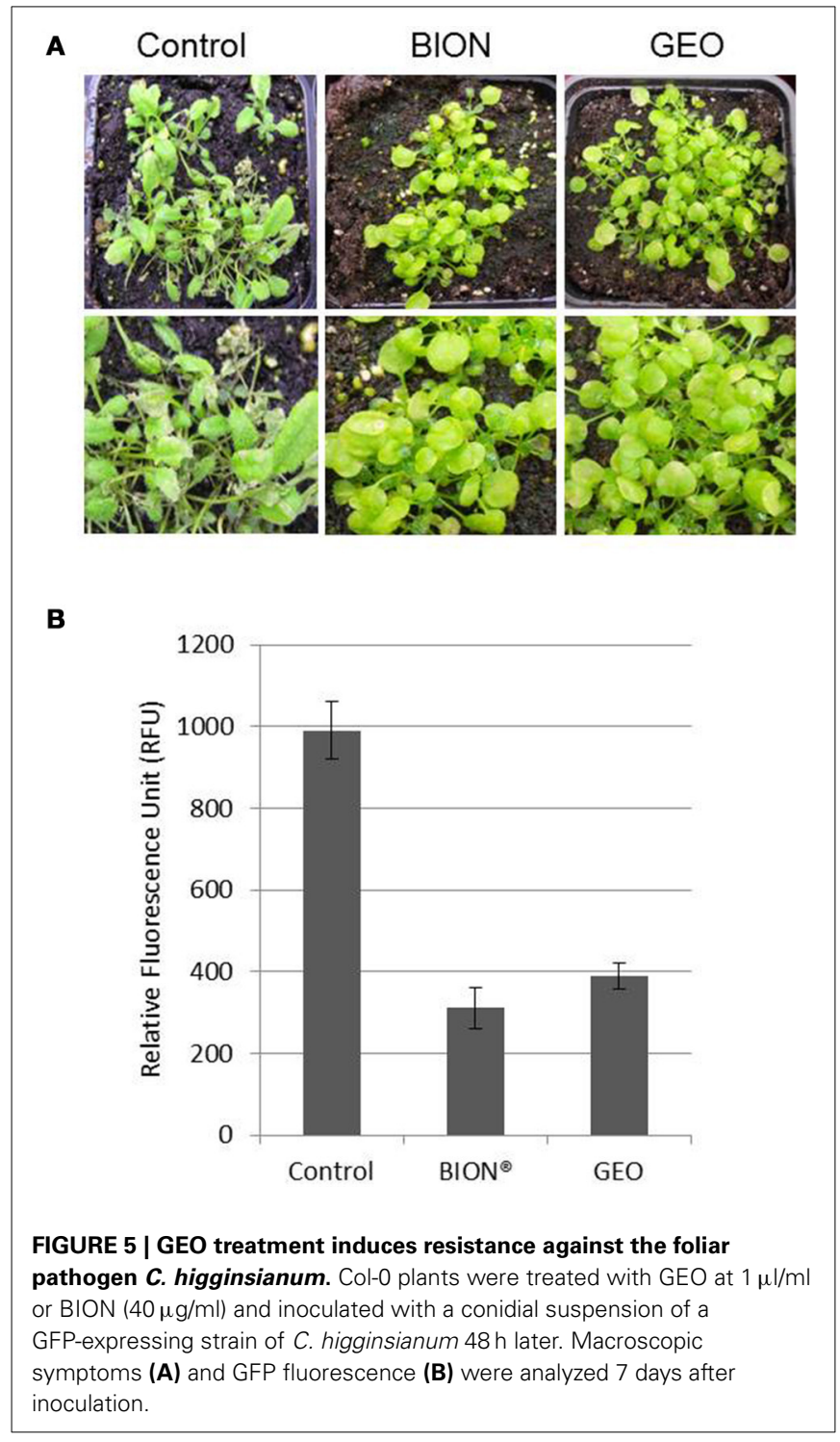

suggesting a role of the SA-dependent pathway in the defense against this fungus (O'Connell et al., 2004). Additionally, benzothiadazole treatments have been shown to reduce anthracnose symptoms on various plants further supporting a role of the SA pathway in Colletotrichum immune responses (Bigirimana and Hofte, 2002; Smith-Becker et al., 2003; Zhu et al., 2008). Thus, this pathosystem was very well-suited to evaluate the impact of GEO treatments on SA-induced plant resistance. In our experimental conditions, GEO was as effective as $\mathrm{BION}^{\circledR}$ to reduce C. higginsianum development.

Interestingly, GEO treatments did not strongly modify the expression of housekeeping genes whereas significant repression of genes coding enzymes involved in primary metabolism was observed after treatment with $\mathrm{BION}^{\circledR}$. Correlatively, no effect on plant growth was observed after repeated application of GEO whereas a significant reduction of plant biomass was obtained with $\mathrm{BION}{ }^{\circledR}$ treatments. The effect of benzothiadazole treatments on plant development is well-documented and has



been associated to a reduction of plant growth and seed production in several plant species (Heil et al., 2000; Cota-Arriola et al., 2013). Negative effects of SA or its synthetic analogs has been attributed to toxic effects of SA and allocation costs (Vos et al., 2013). It is thus surprising that negative effects on plant development were not observed upon GEO treatments. While this point deserves further experimental work, it can be hypothesized that GEO treatment leads to a progressive accumulation of SA inside plant tissues since it required a demethylation step to be converted into an active product. This is not the case for BTH which is directly active on SA receptors (Fu and Dong, 2013).

To conclude, we show here that the essential oil from G. procumbens could be a valuable natural source of MeSA for biocontrol applications. MeSA has been detected in the composition of essential oils from various sources (Flamini et al., 2002; Nebie et al., 2004; Paudel et al., 2013; Radoias and Bosilcov, 2013) but in lower proportion than in GEO and associated with other metabolites which can display toxic effects from the plants or environmental organisms. However, additional assays are required to evaluate the activity of GEO in the field since 
activity of natural compounds can be challenged by environmental conditions and responses to abiotic stresses (Walters and Heil, 2007). Further studies will focus on the development of GEO formulations able to preserve GEO activity during product storage and field treatments.

\section{AUTHOR CONTRIBUTIONS}

Sophie Vergnes and Bernard Dumas designed and performed the experiments and constructed the final manuscript. Sophie Vergnes and Nathalie Ladouce designed and performed the microfluidic Q-PCR experiment. Sophie Vergnes and Sylvie Fournier performed SA analyses and Hicham Ferhout prepared reagents. Bernard Dumas, Hicham Ferhout, and Faouzi Attia initiated and supervised the project.

\section{ACKNOWLEDGMENTS}

This work was done in the frame of the NEOPROTEC project funded by the FUI (Fond Unique Inter-ministériels) and the FEDER (Fonds Européens Pour le Développement Régional). This work was supported by the Centre National de la Recherche Scientifique (CNRS) and the Université Paul Sabatier. We thank the "Toulouse Genomics Platform" for access to the BioMarkTM HD System and helpful discussions.

\section{SUPPLEMENTARY MATERIAL}

The Supplementary Material for this article can be found online at: http://www.frontiersin.org/journal/10.3389/fpls.2014.00477/ abstract

\section{REFERENCES}

Andersen, C. L., Jensen, J. L., and Ørntoft, T. F. (2004). Normalization of real-time quantitative reverse transcription-PCR data: a model-based variance estimation approach to identify genes suited for normalization, applied to bladder and colon cancer data sets. Cancer Res. 64, 5245-5250. doi: 10.1158/00085472.CAN-04-0496

Aviv, D. H., Rusterucci, C., Holt, B. F. 3rd., Dietrich, R. A., Parker, J. E., and Dangl, J. L. (2002). Runaway cell death, but not basal disease resistance, in lsd1 is SA- and NIM1/NPR1-dependent. Plant J. 29, 381-391. doi: 10.1046/j.09607412.2001.01225.x

Bari, R., and Jones, J. D. (2009). Role of plant hormones in plant defence responses. Plant Mol. Biol. 69, 473-488. doi: 10.1007/s11103-008-9435-0

Bigirimana, J., and Hofte, M. (2002). Induction of systemic resistance to Colletotrichum lindemuthianum in bean by a benzothiadiazole derivative and rhizobacteria. Phytoparasitica 30, 159-168. doi: 10.1007/BF02979698

Boller, T., and Felix, G. (2009). A renaissance of elicitors: perception of microbe-associated molecular patterns and danger signals by pattern-recognition receptors. Annu. Rev. Plant Biol. 60, 379-406. doi: 10.1146/annurev.arplant.57.032905.105346

Cota-Arriola, O., Cortez-Rocha, M. O., Burgos-Hernandez, A., Ezquerra-Brauer, J. M., and Plascencia-Jatomea, M. (2013). Controlled release matrices and micro/nanoparticles of chitosan with antimicrobial potential: development of new strategies for microbial control in agriculture. J. Sci. Food Agric. 93, 1525-1536. doi: 10.1002/jsfa.6060

Delaney, T. P., Uknes, S., Vernooij, B., Friedrich, L., Weymann, K., Negrotto, D., et al. (1994). A central role of salicylic acid in plant disease resistance. Science 266, 1247-1250. doi: 10.1126/science.266.5188.1247

Fisher, M. C., Henk, D. A., Briggs, C. J., Brownstein, J. S., Madoff, L. C., Mccraw, S. L., et al. (2012). Emerging fungal threats to animal, plant and ecosystem health. Nature 484, 186-194. doi: 10.1038/nature10947

Flamini, G., Cioni, P. L., and Morelli, I. (2002). Analysis of the essential oil of the aerial parts of Viola etrusca from Monte Labbro (South Tuscany, Italy) and in vivo analysis of flower volatiles using SPME. Flavour Fragr. J. 17, 147-149. doi: 10.1002/ffj.1060
Fu, Z. Q., and Dong, X. (2013). Systemic acquired resistance: turning local infection into global defense. Annu. Rev. Plant Biol. 64, 839-863. doi: 10.1146/annurevarplant-042811-105606

Glazebrook, J. (2005). Contrasting mechanisms of defense against biotrophic and necrotrophic pathogens. Ann. Rev. Phytopathol. 43, 205-227. doi: 10.1146/annurev.phyto.43.040204.135923

Heil, M., Hilpert, A., Kaiser, W., and Linsenmair, K. E. (2000). Reduced growth and seed set following chemical induction of pathogen defence: does systemic acquired resistance (SAR) incur allocation costs? J. Ecol. 88, 645-654. doi: 10.1046/j.1365-2745.2000.00479.x

Hruz, T., Laule, O., Szabo, G., Wessendorp, F., Bleuler, S., Oertle, L., et al. (2008). Genevestigator v3: a reference expression database for the meta-analysis of transcriptomes. Adv. Bioinformatics 2008:420747. doi: 10.1155/2008/420747

Jaulneau, V., Lafitte, C., Corio-Costet, M. F., Stadnik, M. J., Salamagne, S., Briand, X., et al. (2011). An Ulva armoricana extract protects plants against three powdery mildew pathogens. Eur. J. Plant Pathol. 131, 393-401. doi: 10.1007/s10658-011-9816-0

Jaulneau, V., Lafitte, C., Jacquet, C., Fournier, S., Salamagne, S., Briand, X., et al. (2010). Ulvan, a sulfated polysaccharide from green algae, activates plant immunity through the jasmonic acid signaling pathway. J. Biomed. Biotechnol. 10:525291. doi: 10.1155/2010/525291

Jefferson, R. A., Kavanagh, T. A., and Bevan, M. W. (1987). GUS fusions: betaglucuronidase as a sensitive and versatile gene fusion marker in higher plants. EMBO J. 6, 3901-3907.

Klarzynski, O., Descamps, V., Plesse, B., Yvin, J. C., Kloareg, B., and Fritig, B. (2003). Sulfated fucan oligosaccharides elicit defense responses in tobacco and local and systemic resistance against tobacco mosaic virus. Mol. Plant Microbe Interact. 16, 115-122. doi: 10.1094/MPMI.2003.16.2.115

Klarzynski, O., Plesse, B., Joubert, J. M., Yvin, J. C., Kopp, M., Kloareg, B., et al. (2000). Linear b-1,3 glucans are elicitors of defense responses in tobacco. Plant Physiol. 124, 1027-1038. doi: 10.1104/pp.124.3.1027

Lawton, K. A., Friedrich, L., Hunt, M., Weymann, K., Delaney, T., Kessmann, H., et al. (1996). Benzothiadiazole induces disease resistance in Arabidopsis by activation of the systemic acquired resistance signal transduction pathway. Plant J. 10, 71-82. doi: 10.1046/j.1365-313X.1996.10010071.x

Liu, W., Qiao, W., Liu, Z., Wang, X., Jiang, R., Li, S., et al. (2013). Gaultheria: phytochemical and pharmacological characteristics. Molecules 18, 12071-12108. doi: 10.3390/molecules181012071

Mercier, L., Lafitte, C., Borderies, G., Briand, X., Esquerre-Tugaye, M. T., and Fournier, J. (2001). The algal polysaccharide carrageenans can act as an elicitor of plant defence. New Phytol. 149, 43-51. doi: 10.1046/j.1469-8137.2001.00011.x

Nars, A., Rey, T., Lafitte, C., Vergnes, S., Amatya, S., Jacquet, C., et al. (2013). An experimental system to study responses of Medicago truncatula roots to chitin oligomers of high degree of polymerization and other microbial elicitors. Plant Cell Rep. 32, 489-502. doi: 10.1007/s00299-012-1380-3

Nebie, R. H. C., Yameogo, R. T., Belanger, A., and Sib, F. S. (2004). Methyl salycylate, the one constituent of Burkina Faso Securidaca longepedunculata roots bark essential oil. C. R. Chimie 7, 1003-1006. doi: 10.1016/j.crci.2003.12.025

Nikolic, M., Markovic, T., Mojovic, M., Pejin, B., Savic, A., Peric, T., et al. (2013). Chemical composition and biological activity of Gaultheria procumbens L. essential oil. Ind. Crops Prod. 49, 561-567. doi: 10.1016/j.indcrop.2013. 06.002

O’Connell, R., Herbert, C., Sreenivasaprasad, S., Khatib, M., Esquerré-Tugayé, M. T., and Dumas, B. (2004). A novel Arabidopsis-Colletotrichum pathosystem for the molecular dissection of plant-fungal interactions. Mol. Plant Microbe Interact. 17, 272-282. doi: 10.1094/MPMI.2004.17.3.272

Pajerowska-Mukhtar, K. M., Emerine, D. K., and Mukhtar, M. S. (2013). Tell me more: roles of NPRs in plant immunity. Trends Plant Sci. 18, 402-411. doi: 10.1016/j.tplants.2013.04.004

Park, S. W., Kaimoyo, E., Kumar, D., Mosher, S., and Klessig, D. F. (2007). Methyl salicylate is a critical mobile signal for plant systemic acquired resistance. Science 318, 113-116. doi: 10.1126/science.1147113

Paudel, P., Satyal, P., Dosoky, N. S., Maharjan, S., and Setzer, W. N. (2013). Juglans regia and J. nigra, two trees important in traditional medicine: a comparison of leaf essential oil compositions and biological activities. Nat. Prod. Commun. 8, 1481-1486.

Radoias, G., and Bosilcov, A. (2013). Composition of the essential oil from the flowers of Solandra maxima (Sesse boolean AND Moc.) P.S. Green. Flavour Fragr. J. 28, 389-392. doi: 10.1002/ffj.3166 
Shah, J., Chaturvedi, R., Chowdhury, Z., Venables, B., and Petros, R. A. (2014). Signaling by small metabolites in systemic acquired resistance. Plant J. 79, 645-658. doi: 10.1111/tpj.12464

Shapiro, A. D., and Zhang, C. (2001). The role of NDR1 in avirulence gene-directed signaling and control of programmed cell death in Arabidopsis. Plant Physiol. 127, 1089-1101. doi: 10.1104/pp.010096

Smith-Becker, J., Keen, N. T., and Becker, J. O. (2003). Acibenzolar-S-methyl induces resistance to Colletotrichum lagenarium and cucumber mosaic virus in cantaloupe. Crop Prot. 22, 769-774. doi: 10.1016/S0261-2194(03) 00044-9

Van Hulten, M., Pelser, M., Van Loon, L. C., Pieterse, C. M., and Ton, J. (2006). Costs and benefits of priming for defense in Arabidopsis. Proc. Natl. Acad. Sci. U.S.A. 103, 5602-5607. doi: 10.1073/pnas.0510213103

Vernooij, B., Friedrich, L., Morse, A., Reist, R., Kolditz-Jawhar, R., Ward, E., et al. (1994). Salicylic acid is not the translocated signal responsible for inducing systemic acquired resistance but is required in signal transduction. Plant Cell 6, 959-965. doi: 10.1105/tpc.6.7.959

Vlot, A. C., Liu, P. P., Cameron, R. K., Park, S. W., Yang, Y., Kumar, D., et al. (2008). Identification of likely orthologs of tobacco salicylic acid-binding protein 2 and their role in systemic acquired resistance in Arabidopsis thaliana. Plant J. 56, 445-456. doi: 10.1111/j.1365-313X.2008.03618.x

Von Rad, U., Mueller, M. J., and Durner, J. (2005). Evaluation of natural and synthetic stimulants of plant immunity by microarray technology. New Phytol. 165, 191-202. doi: 10.1111/j.1469-8137.2004.01211.x

Vos, I. A., Pieterse, C. M. J., and Van Wees, S. C. M. (2013). Costs and benefits of hormone-regulated plant defences. Plant Pathol. 62, 43-55. doi: 10.1111/ppa.12105

Walters, D., and Heil, M. (2007). Costs and trade-offs associated with induced resistance. Physiol. Mol. Plant Pathol. 71, 3-17. doi: 10.1016/j.pmpp.2007.09.008

Walters, D. R., Ratsep, J., and Havis, N. D. (2013). Controlling crop diseases using induced resistance: challenges for the future. J. Exp. Bot. 64, 1263-1280. doi: $10.1093 /$ jxb/ert026
Wildermuth, M. C., Dewdney, J., Wu, G., and Ausubel, F. M. (2001). Isochorismate synthase is required to synthesize salicylic acid for plant defence. Nature 414, 562-565. doi: 10.1038/35107108

Winter, D., Vinegar, B., Nahal, H., Ammar, R., Wilson, G. V., and Provart, N. J. (2007). An "Electronic Fluorescent Pictograph" browser for exploring and analyzing large-scale biological data sets. PLOS ONE 2:e718. doi: 10.1371/journal.pone.0000718

Yoon, M. Y., Cha, B., and Kim, J. C. (2013). Recent trends in studies on botanical fungicides in agriculture. Plant Pathol. J. 29, 1-9. doi: 10.5423/PPJ.RW.05.2012.0072

Zhu, X., Cao, J., Wang, Q., and Jiang, W. (2008). Postharvest infiltration of $\mathrm{BTH}$ reduces infection of mango fruits (Mangifera indica L. cv. Tainong) by Colletotrichum gloeosporioides and enhances resistance inducing compounds. J. Phytopathol. 156, 68-74. doi: 10.1111/j.1439-0434.2007.01320.x

Conflict of Interest Statement: The authors declare that the research was conducted in the absence of any commercial or financial relationships that could be construed as a potential conflict of interest.

Received: 17 July 2014; accepted: 29 August 2014; published online: 23 September 2014. Citation: Vergnes S, Ladouce N, Fournier S, Ferhout H, Attia F and Dumas B (2014) Foliar treatments with Gaultheria procumbens essential oil induce defense responses and resistance against a fungal pathogen in Arabidopsis. Front. Plant Sci. 5:477. doi: $10.3389 /$ fpls.2014.00477

This article was submitted to Crop Science and Horticulture, a section of the journal Frontiers in Plant Science.

Copyright (c) 2014 Vergnes, Ladouce, Fournier, Ferhout, Attia and Dumas. This is an open-access article distributed under the terms of the Creative Commons Attribution License (CC BY). The use, distribution or reproduction in other forums is permitted, provided the original author(s) or licensor are credited and that the original publication in this journal is cited, in accordance with accepted academic practice. No use, distribution or reproduction is permitted which does not comply with these terms. 